\title{
The Epigenetic Modifier 5-Aza-2-deoxycytidine Triggers the Expression of CD146 Gene in Prostate Cancer Cells
}

\author{
PAULINA DUDZIK, SONIA E. TROJAN, BARBARA OSTROWSKA, GRZEGORZ ZEMANEK, \\ JOANNA DULIŃSKA-LITEWKA, PIOTR LAIDLER and KINGA A. KOCEMBA-PILARCZYK
}

Chair of Medical Biochemistry, Faculty of Medicine, Jagiellonian University - Medical College, Cracow, Poland

\begin{abstract}
Background/Aim: During cancer progression cells undergo epithelial-to-mesenchymal transition (EMT). Although EMT is a complex process, recently, it has been reported that CD146 overexpression in prostate cancer cells is sufficient to induce mesenchymal phenotype. The following study aimed to investigate whether the expression of CD146 is altered by an epigenetic modifier in prostate cancer cells, in vitro. Materials and Methods: Three human prostate cancer cell lines were treated with 5-aza-2-deoxycytidine; the expression of CDI46 and EMT-related factors was analyzed by RT-PCR and western Blot. The methylation status of the CD146 promoter area was assessed using bisulfite sequencing. Results: Our data showed that, the expression of CD146 was evidently increased in all three studied cell lines in response to a demethylating agent, both at the mRNA and protein level, suggesting epigenetic regulation of the analyzed gene. However, there was no methylation in the studied $C p G$ island in CDI46 gene promoter. Moreover, the demethylating agent induced the expression of EMT-related transcription factors (SNAII, SNAI2, TWIST1 and ZEB1), the pattern of which differed among the cell lines, as well as alterations in cell morphology; altogether accounting for the mesenchymal phenotype. Conclusion: The demethylating agent 5-aza-2deoxycytidine triggers the expression of CD146 in prostate cancer cells independently on the methylation status of the analyzed $C p G$ island fragment in CD146 gene promoter. Moreover, demethylation treatment induces a mesenchymal profile in prostate cancer cells.
\end{abstract}

Correspondence to: Kinga Kocemba-Pilarczyk, Ph.D., Chair of Medical Biochemistry, Faculty of Medicine, Jagiellonian University - Medical College, Cracow, Poland. Tel: +48 124227400, e-mail: kinga.kocemba@uj.edu.pl

Key Words: CD146 (MCAM, MUC-18), EMT, epigenetic silencing, DNA methylation.
Mortality from prostate cancer is mainly a consequence of tumor metastasis, during which a local disease is converted into a disseminated and often incurable one (1). During the process of metastasis, cancer cells invade surrounding tissues and form secondary tumors in distal organs $(2,3)$. On the molecular level, down-regulation of cell adhesion molecules, alteration of cell polarity, and reorganization of actin cytoskeleton have been observed in metastatic cells $(2,4)$. These alterations may correspond to epithelial-tomesenchymal transition (EMT), a morphogenetic process in which cells undergo a developmental switch from a polarized epithelial phenotype to a highly motile mesenchymal one. The initial events of this transformation are: the loss of epithelial markers, followed by increased expression of mesenchymal markers, and rearrangement of the actin cytoskeleton $(2,5)$. Several transcription factors, including SNAI1, SNAI2, ZEB1, and TWIST1 trigger the EMT by inhibition of the epithelial phenotype $(2,3)$. Acquisition of the mesenchymal phenotype of enhanced cell motility seems to be the main mechanism underlying metastatic spread of prostate cancer cells (1).

CD146 (MCAM, MUC-18) was initially described in 1987 as a protein involved in invasion and progression of malignant melanoma (6). Recently, its aberrant expression has been implicated in progression and poor overall survival of many cancers including prostate cancer (7). Although it is well established that aberrantly overexpressed CD146 is sufficient to induce mesenchymal phenotype in prostate cancer cells, contributing to the aggressiveness of this tumor (8-10), still little is known about the regulation of its expression in cancer. Thus far, it has been only proven that increased expression of CD146 in tumor tissues is not due to translocation, amplification, or mutation of the respective gene (11).

In this study, using prostate cancer cell lines as a model, we showed that the demethylating agent, 5-aza-2-deoxycytidine can induce CD146 expression and mesenchymal profile in the studied cells. This finding is of very high importance since 5-aza-2-deoxycytidine (decitabine) is still considered in the treatment of solid tumors (12-14), including prostate cancer (15). 
Our results suggest that administration of decitabine may contribute to expansion of cancer cells by promoting EMT. Taking into account the important role of CD146 overexpression in promoting tumor progression (4), including prostate cancer (5-7), the data presented in this manuscript definitely attract attention, and should be taken into consideration, when novel therapeutic strategies with decitabine are being planned.

\section{Materials and Methods}

Cell lines and cell culture. Human prostate cancer cell lines (LNCaP, Du145, and PC3) and human fibroblast (Hs27) cells were obtained from the American Type Culture Collection (Rockville, MD USA). All cells were cultured as described previously (16). Prostate cancer cell lines were cultured in the absence and presence of $10 \mu \mathrm{M} 5$-aza2-deoxycytidine for $144 \mathrm{~h}$. Lengthening of incubation time resulted in a dramatic decrease in cell viability. Fresh medium with or without 5-aza-2-deoxycytidine $(10 \mu \mathrm{M})$ was added every $72 \mathrm{~h}$, according to previously established protocols (17).

In order to visualize the morphology of living cells, images were taken in transmission as well as fluorescent mode after a 15-min incubation with $0.625 \mu \mathrm{g} / \mathrm{ml}$ fluorescein diacetate (FDA), The distribution of green fluorescence derived from Fluorescein in cells was examined in a Carl Zeiss Axioplan II (Oberkochen, Germany) fluorescence microscope integrated with Canon PC1200 camera and AxioVision 4 V 4.6.3.0. Software.

RNA isolation and cDNA synthesis. Total amount of RNA was extracted from cultured cells using RNeasy Plus Mini kit (Qiagen, Hilden, Germany). The concentration and purity of all isolated RNA samples were determined with the use of NanoDrop ND-1000 Spectrophotometer (NanoDrop Technologies, Wilmington, DE, USA). Total RNA ( $1 \mu \mathrm{g})$ was used for cDNA synthesis as described previously (18).

Reverse transcription polymerase chain reaction (RT-PCR). PCR reaction was performed using Color OptiTaq PCR Master Mix (2x) (EURx, Gdansk, Poland) according to the manufacturer's protocol. The PCR mixture was prepared according to the procedure as described previously (18). For all primers used in the study the same PCR conditions were applied as follows: initial denaturation at $95^{\circ} \mathrm{C}$ for $5 \mathrm{~min}$; followed by 30 cycles: $30 \mathrm{~s}$ at $95^{\circ} \mathrm{C}, 30 \mathrm{~s}$ at $58^{\circ} \mathrm{C}$ and $30 \mathrm{~s}$ at $72^{\circ} \mathrm{C}$; and final extension at $72^{\circ} \mathrm{C}$ for $10 \mathrm{~min}$. Electrophoresis on the agarose gel $(1.5 \% \mathrm{w} / \mathrm{v})$ containing ethidium bromide was used for PCR product visualization. Bands were normalized using HPRT. The following primers were used: CD146 forward (5'CCAAGGCAACCTCAGCCATG-3'), CD146 reverse (5'-CTCGAC TCCACAGTCTGGGA-3'), HPRT forward (5'-TGGCGTCGT GATTAGTGATG-3'), HPRT reverse (5'-TATCCAACACTTCGT GGGGT-3'), SNAIl forward (5'-GGATCTCCAGGCTCGAA AGG3') SNAI1 reverse (5'-CATTCGGGAGAAGGTCCGAG-3'), TWIST1 forward (5'-CCGTGGACAGTGATTCCCAG-3'), TWIST1 reverse (5'-CCTTTCAGTGGCTGATTGGC-3'), ZEB1 forward (5'TCCTCGAGGCACCTGAAGAGG'), ZEB1 reverse (5'CAGAGAG GTAAAGCGTTTATAGCC3'), SNAI2 forward (5'GCTACCC AATGGCCTCTCTC3'), SNAI2 reverse (5'TTGCCGCAGATCTTG CAAAC3'). Primers were manufactured by Sigma-Aldrich (St. Louis, MO, USA). Fluorescence signal of ethidium bromide was detected by Bio-Rad ChemiDoc ${ }^{\mathrm{TM}}$ XRS+ System (Bio-Rad, Hercules, CA, USA).
Western blot. The cells were lysed and protein concentration was determined as previously described (19). Protein lysate (30 $\mu \mathrm{g})$ was separated by SDS $10 \%$ PAGE, and subsequently blotted. The detection of CD146 protein was performed with primary mouse anti-CD146 antibody (Cell Signaling, Danvers, MA, USA) and secondary antimouse HRP-linked antibody (Cell Signaling), while mouse monoclonal anti-B-actin antibody (Sigma Aldrich, St. Louis, MO, USA) was used for loading control detection. For visualization of protein expression, ECL $^{\text {тм }}$ Western Blotting Detection Reagents (GE, Healthcare, Chicago, ILL, USA) were used. Chemiluminescence signal was detected by BioRad ChemiDoc ${ }^{\mathrm{TM}}$ XRS+ System (Bio-Rad).

Bisulfite sequencing. Genomic DNA was extracted from LNCaP, Du145, PC3 and Hs27 cells using GenElute Mammalian Genomic DNA Miniprep Kits (Sigma Aldrich) according to the manufacturer's instructions. The quality and concentration of isolated DNA were assessed using the NanoDrop ND-1000 Spectrophotometer (NanoDrop Technologies). Then, $500 \mathrm{ng}$ of DNA was modified by treatment with sodium bisulfite using the EpiTect Fast Bisulfite Kit (Qiagen) according to the manufacturer's instructions. Conversion was performed in a MJ Research PTC-200 Thermal Cycler (Bio-Rad).

The sequence of CD146 gene (11q23.3, NCBI/GRCh38.p12, 119305759-119317130) and its promoter was downloaded from the database of National Center for Biotechnology Information (NCBI). The CpG island in CD146 gene promoter (cg 21096399, NCBI/GRCh38.p12, 119317381-119316788) covers the exon 1, encoding the transcriptional (NCBI/GRCh38.p12, 119317130) and translational (NCBI/GRCh38.p12, 119317101) start sites, as well as the part of 5' upstream region of the coding sequence (20), presenting the typical organization of the genes targeted for epigenetic silencing (21). DNA methylation was assessed in a $\mathrm{CpG}$ island fragment containing $21 \mathrm{CpG}$ sites (out of the $60 \mathrm{CpG}$ dinucleotides present on the specific $\mathrm{CpG}$ island) was assessed using bisulfite sequencing. The region chosen for the analysis covered exon 1 area (including transcriptional and translational start sites) since according to wide genome methylation studies DNA methylation located downstream of the TSS (exon 1 area), is much more tightly linked to transcriptional silencing than the methylation located upstream to TSS (22).

DNA from fibroblasts (Hs27) and commercially available methylated DNA were bisulfite converted (EpiTec Fast Bisulfite Kit, Qiagen) and used as unmethylated and methylated control DNA, respectively. The PCR mixture contained: 100 ng of bisulfite converted DNA, 1×PCR Rxn buffer (Thermo Scientific, Waltham, MA USA), 0.2 $\mathrm{mmol} / \mathrm{l} \mathrm{dNTP}, 1.5 \mathrm{mmol} / 1 \mathrm{MgCl}_{2}, 0.2 \mu \mathrm{mol} / \mathrm{l}$ of each primer, and $2 \mathrm{U}$ Platinum Taq DNA Polymerase (Thermo Scientific). PCR conditions were: initial denaturation at $95^{\circ} \mathrm{C}$ for $5 \mathrm{~min}$; followed by 45 cycles: 30 $\mathrm{s}$ at $95^{\circ} \mathrm{C}, 30 \mathrm{~s}$ at $58^{\circ} \mathrm{C}$, and $30 \mathrm{~s}$ at $72^{\circ} \mathrm{C}$. The reaction was terminated for $10 \mathrm{~min}$ at $72^{\circ} \mathrm{C}$. Primers for bisulfite-converted DNA were as follow: forward (5'-GGGATTTTAGGGAGGAGGTT-3') reverse (5'ATAAAACTTCCCAAACTAATC-3'), amplifying product composed of $200 \mathrm{bp}$. Primers were manufactured by Sigma-Aldrich. The PCR products were separated in electrophoresis on the agarose gel $(1.5 \%$ $w / v)$ containing ethidium bromide, next were cut from the gel and cleaned using QIAquick Gel Extraction (Qiagen). Isolated products were sequenced by Genomed S.A. (Warsaw, Poland).

Densitometry analysis. Densitometry was performed on immunoblot and gel images (Bio-Rad ChemiDoc ${ }^{\mathrm{TM}}$ XRS+ System, Bio-Rad) using the ImageJ gel analysis tool (23). Intensity of each analyzed 

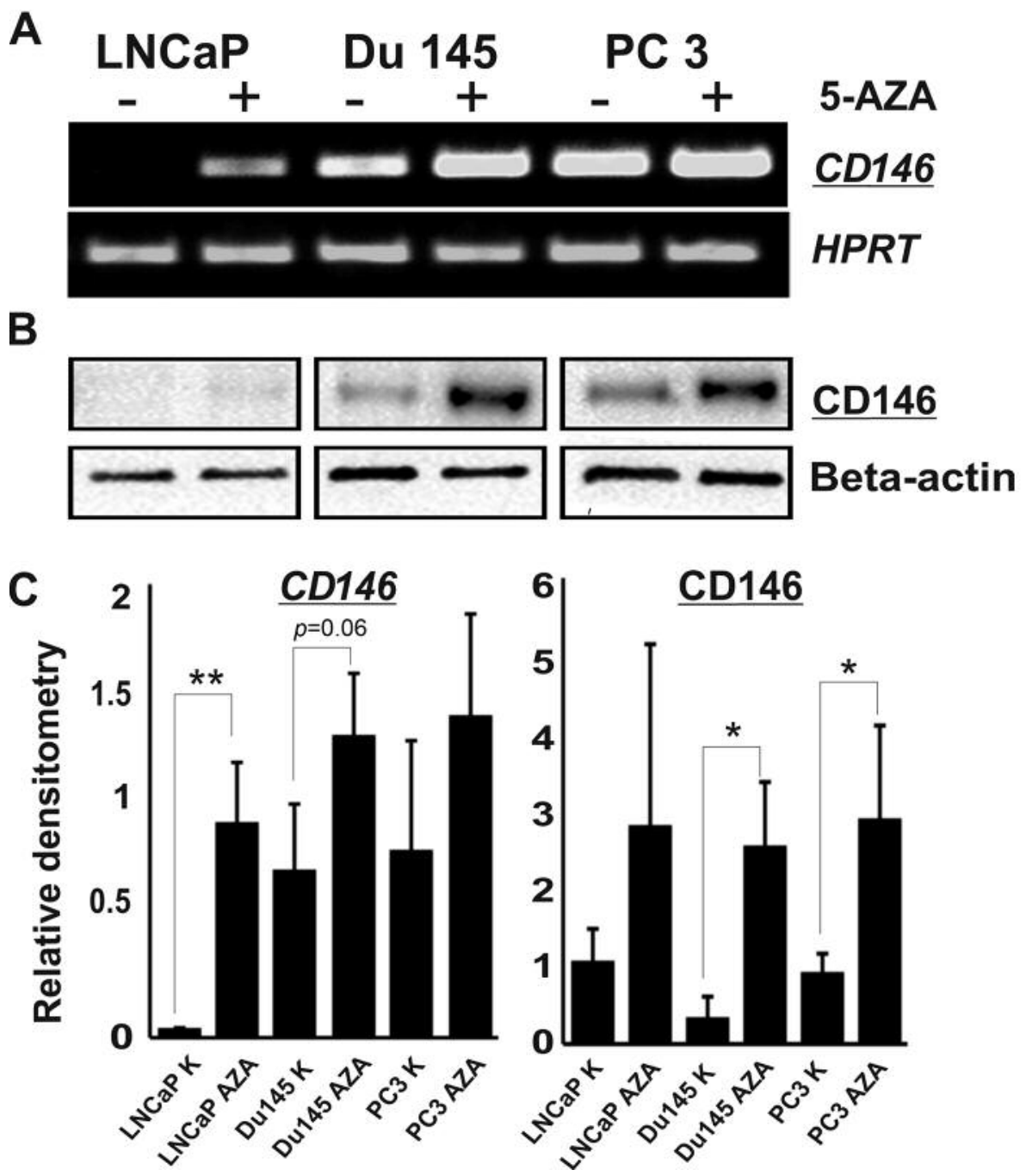

Figure 1. Influence of demethylating agent on the expression of CD146 in prostate cancer cell lines. RT-PCR analysis for CD146 expression in prostate cancer cell lines cultured in the absence and presence of 5-aza-2-deoxycytidine $(10 \mu \mathrm{M})$ for $144 \mathrm{~h}$. HPRT expression was used as an input control (A). Western blot analysis for CD146 expression in prostate cancer cell lines cultured in the absence and presence of 5-aza-2-deoxycytidine (10 $\mu M)$ for $144 \mathrm{~h}$. Beta-actin expression was used as a loading control (B). Densitometry analysis of RT-PCR bands intensity normalized to HPRT. Each relative densitometry value is the average from three independent experiments. The mean $\pm S D$ is shown. ${ }^{*} p<0.01$, by student's $t$-test, $p$-value between 0.05 and 0.1 was considered as an indication of a trend $(C$, left). Densitometry analysis of western blot band intensity normalized to beta-actin. Each relative densitometry value is the average from three independent experiments. The mean $\pm S D$ is shown. ${ }^{*}<0.05$ by student's $t$-test $(C$, right).

RT-PCR and Western blot band was normalized to corresponding HPRT and beta-actin control band, respectively.

Statistical analysis. The Student's $t$-test was used to evaluate differences in expression of CD146 and mesenchymal transcription factors between control cells and the cells treated with 5-aza-2-deoxycytidine. RT-PCR and Western blot bands intensity was normalized to corresponding HPRT and beta-actin bands, respectively. All results are presented as experimental mean values of three independent experiments. All $p$ values $>0.05$ are considered statistically significant.

\section{Results}

Treatment with of 5-aza-2-deoxycytidine increased CD146 expression in prostate cancer cell lines. Initially, we estimated the influence of the demethylating agent, 5-aza-2deoxycytidine, on $C D 146$ expression in three prostate cancer cell lines: LNCaP, Du145, and PC3. As shown in Figure1A, the analyzed cell lines differed in the basal level of CD146 mRNA. In case of LNCaP cell line, the one with epithelial 

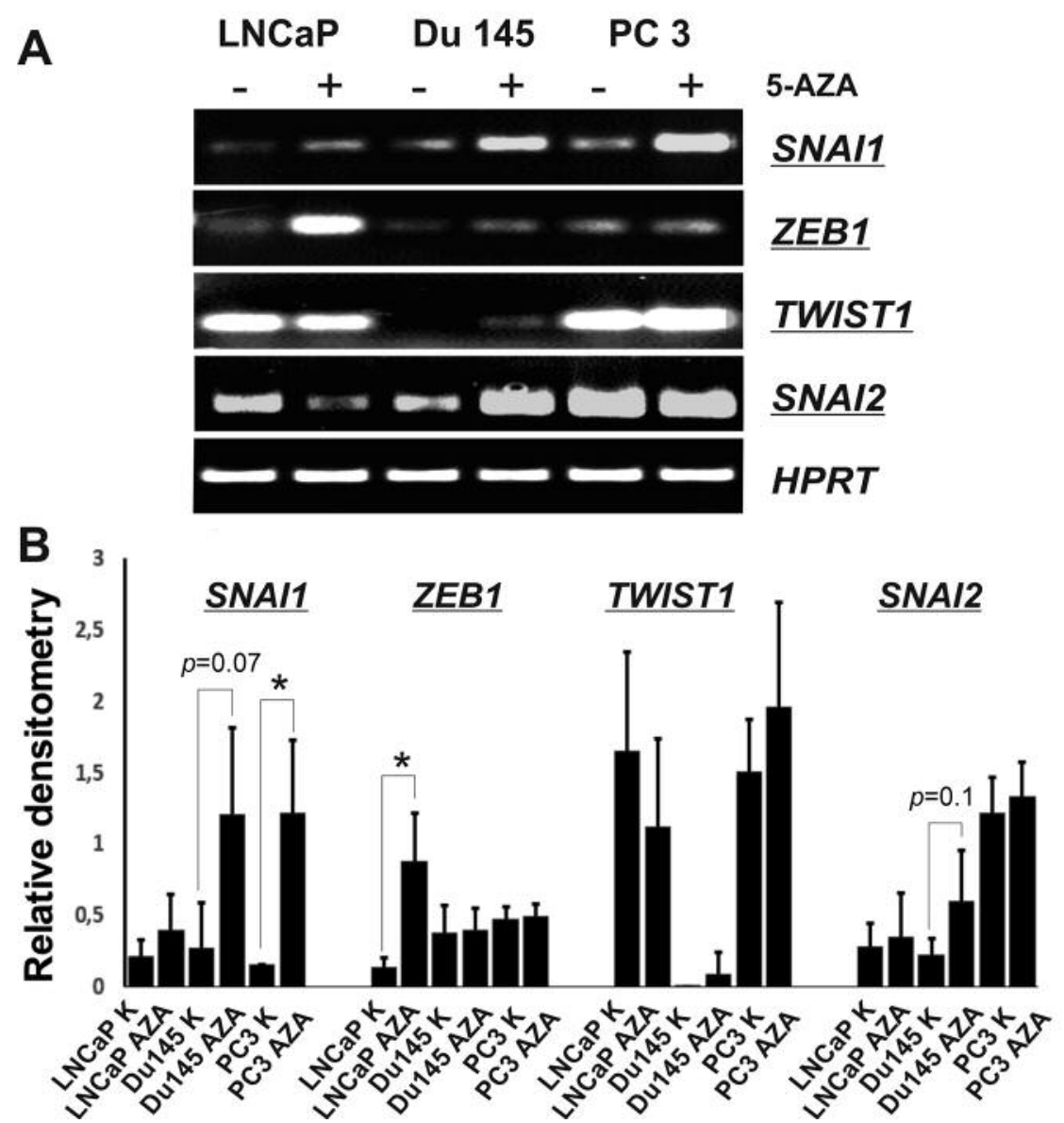

Figure 2. Effect of demethylating agent on the expression of mesenchymal markers in prostate cancer cell lines. RT-PCR analysis for EMT markers expression in prostate cancer cell lines cultured in the absence and presence of 5-aza-2-deoxycytidine (10 $\mu M)$ for 144 h. HPRT expression was used as input control. The representative experiment of 3 independent experiments is shown (A). Densitometry analysis of RT-PCR bands intensity normalized to HPRT imaged with Bio-Rad ChemiDoc ${ }^{T M} X R S+$ System (Bio-Rad). Each relative densitometry value is the average from three independent experiments. The mean $\pm S D$ is shown. ${ }^{*} p<0.05$, by student's $t$-test, $p$-value between 0.05 and 0.1 was considered as an indication of a trend $(B)$.

characteristics, CD146 expression was not detectable, whereas it was clearly visible in Du145 and PC3 cell lines, displaying mesenchymal features $(24,25)$. Interestingly, in response to treatment with 5-aza-2-deoxycytidine, CD146 expression was evidently induced in all three analyzed cell lines. The RT-PCR results were subsequently confirmed by Western blot. As shown in Figure 1B, in accordance with mRNA expression data, the level of CD146 protein was also increased in all three prostate cancer cell lines after demethylation treatment.

Effect of demethylating treatment on the expression of EMT markers in prostate cancer cell lines. Next, in order to determine whether demethylating treatment triggers the mesenchymal profile in prostate cancer cells, we analyzed the expression of transcription factors regulating the EMT, SNAI1, SNAI2, TWIST1 and ZEB1 in cells treated with 5-aza- 2-deoxycytidine. As shown in Figure 2, SNAI1 (Snail) was induced in all the studied cell lines, whereas TWIST1 was triggered only in those with mesenchymal characteristics (Du145 and PC3) $(24,25)$. Increase in expression of SNAI2 (Slug) was observed exclusively in Du145, whereas overexpression of ZEB1 upon demethylation treatment was apparent only in LNCaP. Interestingly, all the analyzed mesenchymal transcription factors, except ZEB1, were clearly triggered in the Du145 cell line presenting semi-mesenchymal characteristics (26). In LNCaP cell line, reported as epithelial, our data revealed that 2 (SNAII and ZEB1) out of the 3 transcription factors exhibiting low basal expression (SNAI1, $Z E B 1$, and $S N A I 2)$ were clearly induced. Having observed that 5 aza-2-deoxycytidine triggers EMT transcriptional program, we subsequently analyzed the alteration in morphology of LNCaP, Du145 and PC3 cells under the 


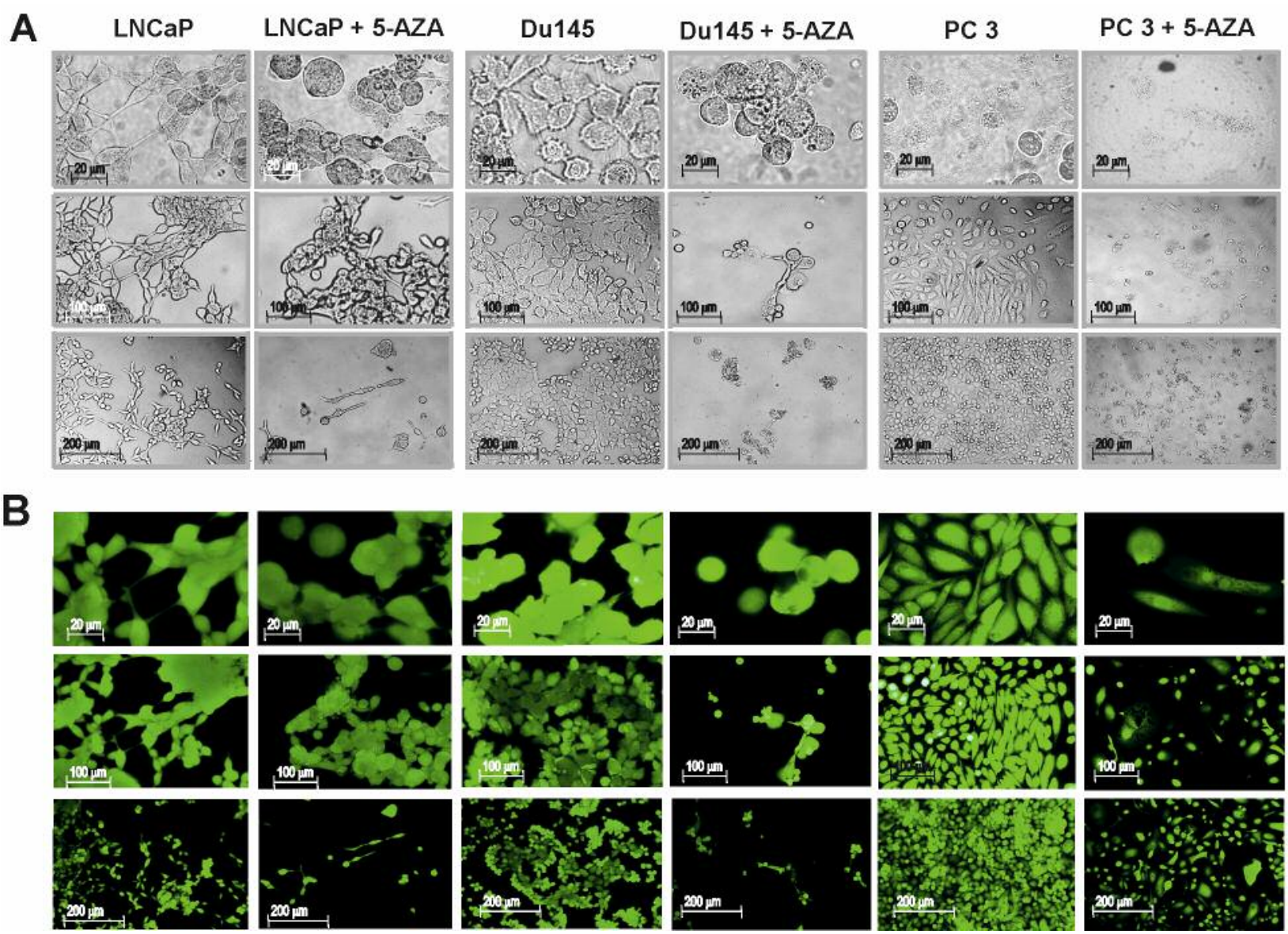

Figure 3. Morphological features of prostate cancer cell lines after treatment with a demethylating reagent. The LNCaP, Du145 and PC3 cells were cultured in the absence or presence of 5-aza-2-deoxycytidine $(10 \mu \mathrm{M})$ for $144 \mathrm{~h}$ and were photographed under a fluorescent microscope. Fluorescein diacetate (FDA) was used as a vital stain to assay cell viability.

treatment with 5-aza-2-deoxycytidine. As shown in Figure 3, the analyzed cells became more round and got circular morphology, what confirms that they acquired/strengthened the mesenchymal features.

Analysis of CD146 gene promoter methylation in prostate cancer cell lines. Since application of demethylation agent triggered the expression of CD146 in all studied prostate cancer cell lines, we hypothesized that $\mathrm{CpG}$ island methylation of CD146 gene promoter may control its expression in prostate cancer cells. Hence, we studied the methylation status of CDI46 gene promoter region, including the $\mathrm{CpG}$ island covering the transcriptional start site using direct bisulfite-sequencing PCR. In Figure 4A the localization of $\mathrm{CpG}$ island (cg21096399, 11q23.3, NCBI/GRCh38.p12, 119317381-119316788) encompassing exon 1 and the upstream region of the transcription start site (TSS, NCBI/GRCh38.p12, 119317130) in CD146 gene promoter is shown. In vitro methylated DNA and DNA isolated from normal human fibroblasts were used as methylated and unmethylated control, respectively, to validate our experimental setup. As determined in Figure 4B, direct bisulfite-sequencing PCR revealed that the analyzed $\mathrm{CpG}$ island fragment was unmethylated in all the studied prostate cancer cell lines. However, methylation in different areas than bona fide $\mathrm{CpG}$ island might be involved in $C D 146$ expression silencing in prostate cancer cell lines.

The relation between CD146 expression and mesenchymal markers in prostate cancer patients. In order to reveal the relation between the CD146 expression and mesenchymal profile in primary tumors, we analyzed three independent publicly available transcriptome data sets. The strength of the relationship between the mesenchymal markers and CD146 gene expression was measured using the Spearman rank correlation method. As determined in Table I, we found that $S N A I 2$ and ZEB2 were significantly positively correlated with CD146 in all analyzed data sets; in two out of three data sets, 


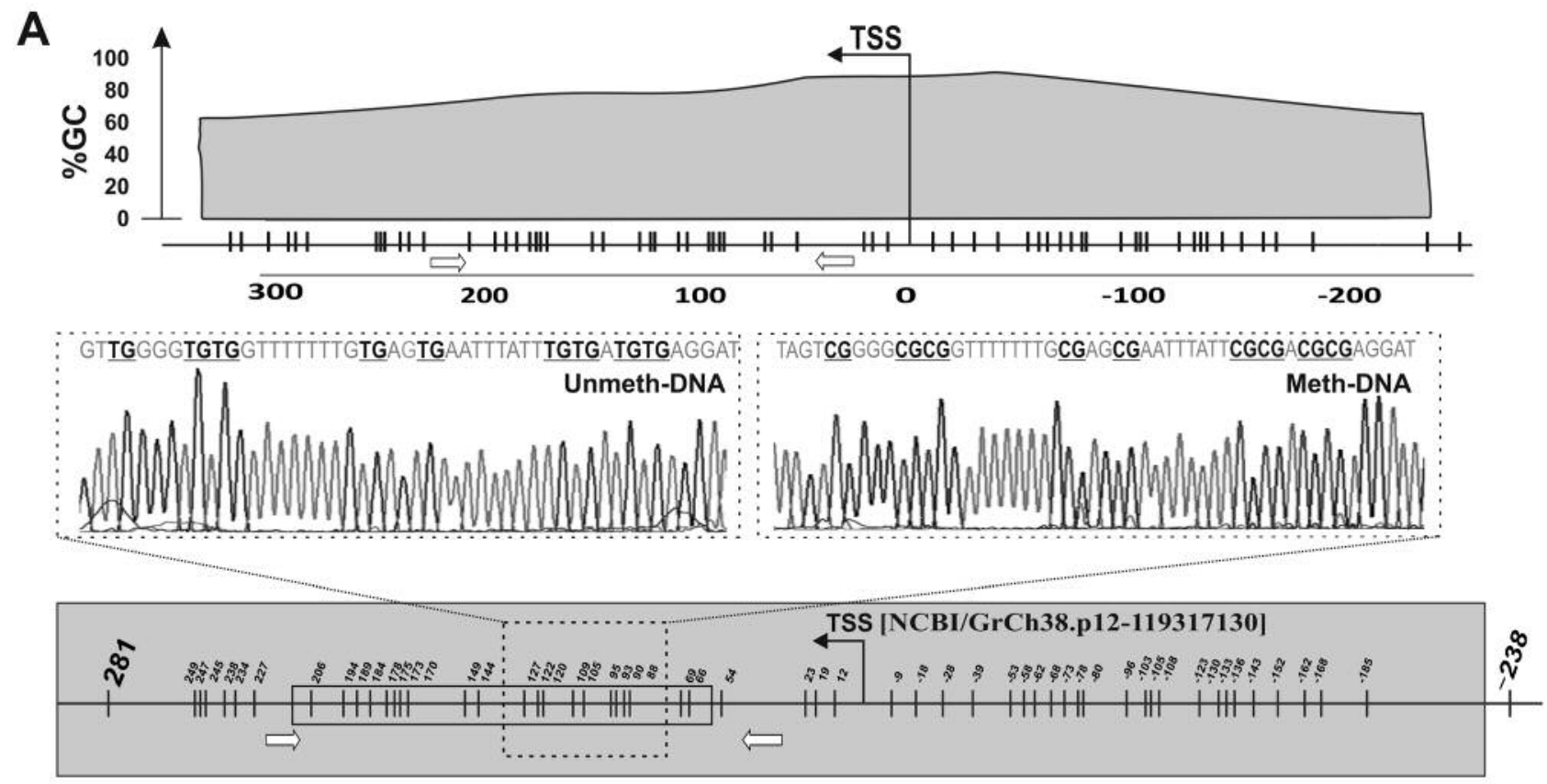

B

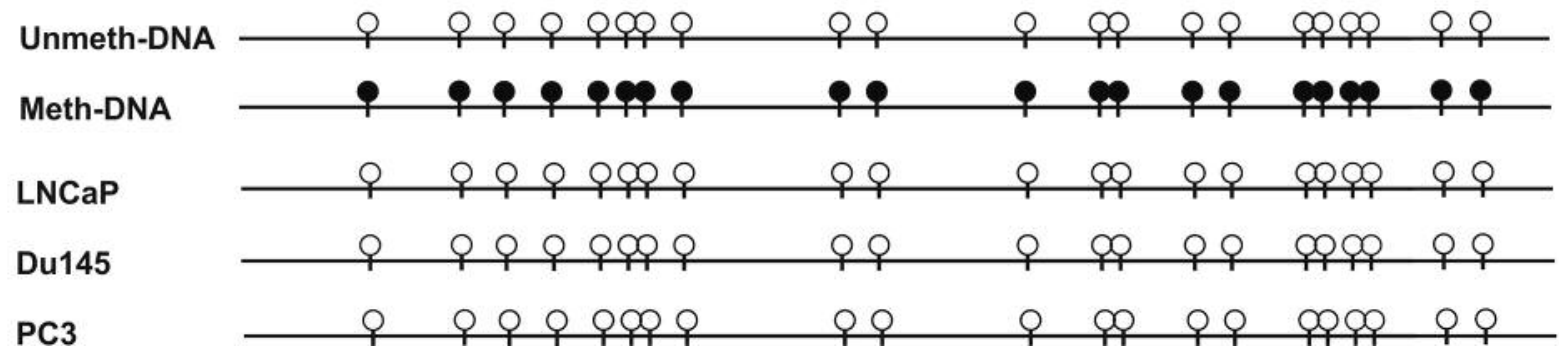

Figure 4. Localization and analysis of methylation status of CpG island in the promoter area of CD146 gene. Schematic representation of the analyzed CD146 gene promoter area, containing a CpG island (marked in grey) encompassing transcription start site (TSS). White arrows indicate the positions of primers used for bisulfite sequencing of $\mathrm{Cp} G$ island area. Representation of bisulfite genomic sequencing results of the CD146 promoter $C p G$ island region in normal human fibroblast and commercially available in vitro methylated DNA, used as unmethylated control DNA (Unmeth-DNA) and methylated control DNA (Meth-DNA), respectively (A). Analysis of methylation pattern in CD146 gene promoter. The figure shows representative fragment of direct bisulfite genomic sequencing results of the PCR product with 21 CpG dinucleotides (CpGs) within the CpG island, open circles indicate unmethylated CpG sites whereas closed circle indicate methylated sites $(B)$.

the $C D 146$ expression was significantly correlated with $Z E B 1$ and TWIST2, whereas the CD146 was positively correlated with SNAII only in one data set. Altogether, our analysis indicated that there is a relationship between $C D 146$ overexpression and mesenchymal profile in prostate cancer patients.

\section{Discussion}

To the best of our knowledge, this is the first study to demonstrate that a demethylating agent can induce the expression of CD146 in parallel to EMT-related transcription factors in prostate cancer cells, in vitro. Although it was not directly proven that the mesenchymal profile in prostate cancer cells was induced by CD146 overexpression, there are numerous studies showing that a high level of CD146 is linked to metastasis and progression of this cancer (8-10). Specifically, Wu et al. reported that CD146 was highly expressed in human high-grade prostatic intraepithelial neoplasia tissue sections in comparison to weak expression in prostatic epithelial cells and the normal prostate gland (8). They also revealed that CD146 expression correlates with the in vitro cell motility and invasiveness in human prostate cancer cell lines, as well as with in vivo metastasis in a mouse model (9). Moreover, in a subsequent paper of the same group, it was 
Table I. Correlation between epithelial-to-mesenchymal transition (EMT) markers and CD146 expression.

\begin{tabular}{|c|c|c|c|c|c|c|}
\hline \multirow{2}{*}{$\begin{array}{l}\text { Number of } \\
\text { patients } \\
\text { Source }\end{array}$} & \multicolumn{2}{|c|}{497} & \multicolumn{2}{|c|}{72} & \multicolumn{2}{|c|}{370} \\
\hline & \multicolumn{2}{|c|}{ TCGA } & \multicolumn{2}{|c|}{ GEO } & \multicolumn{2}{|c|}{ GEO } \\
\hline ID & \multicolumn{2}{|c|}{ PRAD } & \multicolumn{2}{|c|}{ GSE2109 } & \multicolumn{2}{|c|}{ GSE21034 } \\
\hline Gene & $R$ value & $p$-Value & $R$ value & $p$-Value & $R$ value & $p$-Value \\
\hline Twist1 & $X$ & & $\mathrm{X}$ & & $\mathrm{X}$ & \\
\hline Twist2 & 0.655 & $* * *$ & 0.739 & $* * *$ & $\mathrm{X}$ & \\
\hline Snail & 0.536 & $* * *$ & $\mathrm{X}$ & & $X$ & \\
\hline Snai2 & 0.524 & $* * *$ & 0.5 & $* * *$ & 0.717 & $* * *$ \\
\hline Zeb1 & 0.751 & $* * *$ & $\mathrm{X}$ & & 0.809 & $* * *$ \\
\hline Zeb2 & 0.666 & $* * *$ & 0.481 & $* * *$ & 0.702 & $* * *$ \\
\hline
\end{tabular}

***p-value $<0.001 . \mathrm{X}$, No significant correlation.

shown that ectopic expression of CD146 in epithelial human cancer LNCaP cell line increases its metastatic potential in mouse model (10). This observation was in accordance with the study by Zeng et al., who revealed that ectopic expression of CD146 in epithelial breast cancer cells leads to up-regulation of mesenchymal markers, significantly promoting cell migration and invasion (27). Taking into consideration all the evidence, one may assume that the expression of mesenchymal transcription factors in analyzed prostate cancer cell lines was triggered by the CD146 overexpression induced by the demethylating agent; however, additional experiments are necessary to prove this concept. In view of foregoing, we hypothesize that DNA methylation may be the universal mechanism which controls expression of CD146 in prostate cancer cells. Importantly, in 2008 Liu et al., using methylationspecific PCR revealed that CD146 is a target for aberrant promoter methylation, suggesting that this epigenetic mechanism may be involved in the aberrant expression of this gene (28). Surprisingly, however, they reported a correlation between $C D 146$ overexpression and hypermethylation of the gene promoter $\mathrm{CpG}$ island in advanced prostate cancer (28). These data were contradictory to the dogma that $\mathrm{CpG}$ island promoter methylation leads to transcriptional silencing (29-31). Apparently, our detailed analysis of the publication by Liu et $a l$., revealed that these authors incorrectly defined the position of $\mathrm{CpG}$ island area, and they analyzed area outside the bona fide $\mathrm{CpG}$ island of CD146 gene promoter. The proper localization of $\mathrm{CpG}$ island in the CD146 gene promoter was published by our group in 2016 (20). Nevertheless, although Liu et al. incorrectly localized the $\mathrm{CpG}$ island, their observation that methylation status in the promoter area varied dependently on the disease stage may suggest that the pattern of methylation changes during prostate cancer progression, hence indicating involvement of epigenetics regulation of
CD146 gene expression. Of note, differential methylation in CD146 gene promoter was also revealed in epigenome-wide association studies, in which DNA methylation profile was assayed in clinical samples of prostate cancer patients $(32,33)$. For instance, a study by Kobayashi et al. on 95 primary prostate tumors and 86 benign adjacent prostate tissue samples showed increased methylation in the $C D 146$ promoter area in prostate cancer cells compared to their benign counterpart. In total, this study revealed 4,004 gene promoters with statistically different DNA methylation status between tumors and benign adjacent prostate tissues; for some of them, including CD146 gene promoter, initial data obtained by Illumina HumanMethylation27 platform were validated by pyrosequencing (32). The validation experiment confirmed higher degree of methylation in prostate cancer in comparison to normal tissues in the position -238 do -385 in relation to TSS of CD146 gene (32), which was in proximity (but it did not cover) to the area analyzed by Liu et al. (-457 do -556 in relation to TSS of CD146 gene) (28). In another genome-wide DNA methylation study, Kim et al. (33) using MethylPlexnext-generation sequencing (M-NGS) technology identified 6,619 promoter methylation events (within \pm 1500 bp flanking the TSS) present in either normal, benign adjacent, localized, or metastatic prostate cancer tissue samples. Importantly, CD146 gene promoter was on the list of 6,619 gene promoters selected by this approach. In particular, Kim et al. reported a complete lack of methylation in CD146 gene promoter area ( \pm 1500 in relation to TSS) in 2 normal tissues, as well as the presence of methylation in exon 1 (900 to 1500 in relation to TSS) in some patients with benign, localized, and metastatic tumors. In addition, in some patients with localized and advanced tumor the methylation was present also in a region (-600 to 0 in relation to TSS) covering the $\mathrm{CpG}$ island area (33). Even though both research groups, Kobayashi et al. and Kim et al., reported different methylation status of CD146 gene promoter area in cancerous tissues in comparison to benign and normal counterparts, the analysis of gene expression was not performed in studied tissues samples, thus it is not possible to conclude whether the methylation in the reported areas anywise affects the expression of CD146 $(32,33)$. Since our present data revealed that the $\mathrm{CpG}$ island covering exon 1 , the area tightly linked to transcriptional silencing (22), was unmethylated, we hypothesize that DNA methylation outside this $\mathrm{CpG}$ island might be responsible for the control of the CD146 gene expression. Of note, recent studies in the field of epigenetics revealed that methylation in the upstream and downstream $\mathrm{CpG}$ island shores (up to $\pm 1500 \mathrm{bp}$ ) inhibits gene transcription in cancer cells, whereas $\mathrm{CpG}$ island stays as unmethylated $(34,35)$. Furthermore, in a recent publication, Skvortsova et al. reported that $\mathrm{CpG}$ islands in prostate and breast cancer cells display partial methylation encroachment across the 5' or 3' CpG island borders, which is associated with transcriptional silencing of gene expression (36). 


\section{Conclusion}

For the first time, it was shown that demethylation treatment induces $C D 146$ expression in prostate cancer cells, although the DNA methylation in the analyzed $\mathrm{CpG}$ island area was not detected. We also revealed that overexpression of CD146 significantly correlates with mesenchymal profile of prostate cancer cells, which has previously been confirmed by someone else. In fact, there were studies showing that CD146 induces motility, aggressiveness and invasiveness in prostate cancer, as we described in introduction, but we have confirmed for the first time that mesenchymal transcription factors' expression correlates with CD146 expression in prostate cancer cells (cell lines and primary tumors). These data seem to be of great importance since, apart from its low efficacy in initial clinical trials, decitabine (5-aza-2deoxycytidine) is still considered in the solid tumor therapy (12-14). Moreover, recently, epigenetic therapy has been proposed as a novel approach in the treatment of prostate cancer (15). Our findings suggest that decitabine triggers the expression of CD146, a very potent EMT inducer in prostate cancer cells, indicating that the therapeutic strategies focused on demethylating agents should be carefully re-considered before application to prostate cancer patients.

\section{Acknowledgements}

Work presented in this paper was funded by the statutory grants (K/ZDS/007983), (K/ZDS/008378), (K/ZDS/008379) and (K/ZDS/008402).

\section{Authors' Contributions}

PD and KAKP designed the research and performed the majority of experiments. PD, KAKP, BO wrote the manuscript. PD, SET, BO, JDL and GZ performed the experiments and analyzed data. PL critically reviewed the manuscript. All authors interpreted the data and corrected the manuscript.

\section{References}

1 Odero-Marah V, Hawsawi O, Henderson V and Sweeney J: Epithelial-mesenchymal transition (EMT) and prostate cancer. Adv Exp Med Biol 1095: 101-110, 2018. PMID: 30229551. DOI: $10.1007 / 978-3-319-95693-0 \_6$

2 Pastushenko I and Blanpain C: EMT transition states during tumor progression and metastasis. Trends Cell Biol 29(3): 212226, 2019. PMID: 30594349. DOI: 10.1016/j.tcb.2018.12.001

3 Pastushenko I, Brisebarre A, Sifrim A, Fioramonti M, Revenco T, Boumahdi S, Van Keymeulen A, Brown D, Moers V, Lemaire S, De Clercq S, Minguijon E, Balsat C, Sokolow Y, Dubois C, De Cock F, Scozzaro S, Sopena F, Lanas A, D'Haene N, Salmon I, Marine JC, Voet T, Sotiropoulou PA and Blanpain C: Identification of the tumour transition states occurring during EMT. Nature 556(7702): 463-468, 2018. PMID: 29670281. DOI: $10.1038 / \mathrm{s} 41586-018-0040-3$
4 Das V, Bhattacharya S, Chikkaputtaiah C, Hazra S and Pal M: The basics of epithelial-mesenchymal transition (EMT): A study from a structure, dynamics, and functional perspective. J Cell Physiol, 2019. PMID: 30723913. DOI: 10.1002/jcp.28160

5 Serrano-Gomez SJ, Maziveyi M and Alahari SK: Regulation of epithelial-mesenchymal transition through epigenetic and posttranslational modifications. Mol Cancer 15: 18, 2016. PMID: 26905733. DOI: $10.1186 / \mathrm{s} 12943-016-0502-\mathrm{x}$

6 Lehmann JM, Holzmann B, Breitbart EW, Schmiegelow P, Riethmuller G and Johnson JP: Discrimination between benign and malignant cells of melanocytic lineage by two novel antigens, a glycoprotein with a molecular weight of 113,000 and a protein with a molecular weight of 76,000. Cancer Res 47(3): 841-845, 1987. PMID: 3542195.

7 Zeng P, Li H, Lu PH, Zhou LN, Tang M, Liu CY and Chen MB: Prognostic value of CD146 in solid tumor: A systematic review and meta-analysis. Sci Rep 7(1): 4223, 2017. PMID: 28652617. DOI: $10.1038 / \mathrm{s} 41598-017-01061-3$

8 Wu GJ, Varma VA, Wu MW, Wang SW, Qu P, Yang H, Petros JA, Lim SD and Amin MB: Expression of a human cell adhesion molecule, MUC18, in prostate cancer cell lines and tissues. Prostate 48(4): 305-315, 2001. PMID: 11536311.

9 Wu GJ, Wu MW, Wang SW, Liu Z, Qu P, Peng Q, Yang H, Varma VA, Sun QC, Petros JA, Lim SD and Amin MB: Isolation and characterization of the major form of human MUC18 cDNA gene and correlation of MUC18 over-expression in prostate cancer cell lines and tissues with malignant progression. Gene 279(1): 17-31, 2001. PMID: 11722842.

10 Wu GJ, Peng Q, Fu P, Wang SW, Chiang CF, Dillehay DL and Wu MW: Ectopical expression of human MUC18 increases metastasis of human prostate cancer cells. Gene 327(2): 201213, 2004. PMID: 14980717. DOI: 10.1016/j.gene.2003.11.018

11 Wang Z and Yan X: CD146, a multi-functional molecule beyond adhesion. Cancer Lett 330(2): 150-162, 2013. DOI: 10.1016/ j.canlet.2012.11.049

12 Zhang Y, Mei Q, Liu Y, Li X, Brock MV, Chen M, Dong L, Shi L, Wang Y, Guo M, Nie J and Han W: The safety, efficacy, and treatment outcomes of a combination of low-dose decitabine treatment in patients with recurrent ovarian cancer. Oncoimmunology 6(9): e1323619, 2017. PMID: 28932630. DOI: $10.1080 / 2162402 X .2017 .1323619$

13 Linnekamp JF, Butter R, Spijker R, Medema JP and van Laarhoven HWM: Clinical and biological effects of demethylating agents on solid tumours - a systematic review. Cancer Treat Rev 54: 10-23, 2017. PMID: 28189913. DOI: 10.1016/j.ctrv.2017.01.004

$14 \mathrm{Xu} \mathrm{P}, \mathrm{Hu} \mathrm{G}$, Luo $\mathrm{C}$ and Liang Z: DNA methyltransferase inhibitors: An updated patent review (2012-2015). Expert Opin Ther Pat 26(9): 1017-1030, 2016. PMID: 27376512. DOI: 10.1080/13543776.2016.1209488

15 Motawi TK, Darwish HA, Diab I, Helmy MW and Noureldin $\mathrm{MH}$ : Combinatorial strategy of epigenetic and hormonal therapies: A novel promising approach for treating advanced prostate cancer. Life Sci 198: 71-78, 2018. PMID: 29455003. DOI: $10.1016 / \mathrm{j} .1 \mathrm{fs} .2018 .02 .019$

16 Dudzik P, Dulinska-Litewka J, Wyszko E, Jedrychowska P, Opalka M, Barciszewski J and Laidler P: Effects of kinetin riboside on proliferation and proapoptotic activities in human normal and cancer cell lines. J Cell Biochem 112(8): 2115-2124, 2011. PMID: 21465535. DOI: $10.1002 / \mathrm{jcb} .23132$ 
17 Ramachandran K, Speer C, Nathanson L, Claros M and Singal $\mathrm{R}$ : Role of DNA methylation in cabazitaxel resistance in prostate cancer. Anticancer Res 36(1): 161-168, 2016. PMID: 26722040.

18 Trojan SE, Piwowar M, Ostrowska B, Laidler P and KocembaPilarczyk KA: Analysis of malignant melanoma cell lines exposed to hypoxia reveals the importance of pfkfb4 overexpression for disease progression. Anticancer Res 38(12): 6745-6752, 2018. PMID: 30504385. DOI: 10.21873/ anticanres.13044

19 Kocemba-Pilarczyk KA, Ostrowska B, Trojan S, Aslan E, Kusior D, Lasota M, Lenouvel C and Dulinska-Litewka J: Targeting the hypoxia pathway in malignant plasma cells by using 17allylamino-17-demethoxygeldanamycin. Acta Biochim Pol 65(1): 101-109, 2018. PMID: 29543923. DOI: 10.18388/abp.2017_1630

20 Kocemba KA, Dudzik P, Ostrowska B and Laidler P: Incorrect analysis of mcam gene promoter methylation in prostate cancer. Prostate 76(15): 1464-1465, 2016. PMID: 27418327. DOI: $10.1002 /$ pros. 23210

21 Feltus FA, Lee EK, Costello JF, Plass C and Vertino PM: Predicting aberrant cpg island methylation. Proc Natl Acad Sci USA 100(21): 12253-12258, 2003. PMID: 14519846. DOI: 10.1073/pnas.2037852100

22 Brenet F, Moh M, Funk P, Feierstein E, Viale AJ, Socci ND and Scandura JM: Dna methylation of the first exon is tightly linked to transcriptional silencing. PLoS One 6(1): e14524, 2011 PMID: 21267076. DOI: 10.1371/journal.pone.0014524

23 Abramoff MD, Magelhaes PJ and Ram SJ: Image processing with imagej. Biophotonics International 11(7): 36-42, 2004.

24 Lowes LE, Goodale D, Xia Y, Postenka C, Piaseczny MM, Paczkowski F and Allan AL: Epithelial-to-mesenchymal transition leads to disease-stage differences in circulating tumor cell detection and metastasis in pre-clinical models of prostate cancer. Oncotarget 7(46): 76125-76139, 2016. PMID: 27764810. DOI: 10.18632 oncotarget.12682

25 Lo UG, Lee CF, Lee MS and Hsieh JT: The role and mechanism of epithelial-to-mesenchymal transition in prostate cancer progression. Int J Mol Sci 18(10): pii: E20792017. PMID: 28973968. DOI: 10.3390/ijms18102079

26 Pulukuri SM, Gondi CS, Lakka SS, Jutla A, Estes N, Gujrati M and Rao JS: Rna interference-directed knockdown of urokinase plasminogen activator and urokinase plasminogen activator receptor inhibits prostate cancer cell invasion, survival, and tumorigenicity in vivo. J Biol Chem 280(43): 36529-36540, 2005. PMID: 16127174. DOI: 10.1074/jbc.M503111200

27 Zeng Q, Li W, Lu D, Wu Z, Duan H, Luo Y, Feng J, Yang D, Fu $\mathrm{L}$ and Yan X: Cd146, an epithelial-mesenchymal transition inducer, is associated with triple-negative breast cancer. Proc Natl Acad Sci USA 109(4): 1127-1132, 2012. PMID: 22210108. DOI: $10.1073 /$ pnas.1111053108

28 Liu JW, Nagpal JK, Jeronimo C, Lee JE, Henrique R, Kim MS, Ostrow KL, Yamashita K, van Criekinge V, Wu G, Moon CS, Trink $\mathrm{B}$ and Sidransky D: Hypermethylation of mcam gene is associated with advanced tumor stage in prostate cancer. Prostate 68(4): 418426, 2008. PMID: 18196513. DOI: 10.1002/ pros.20709
29 Boyes J and Bird A: Repression of genes by DNA methylation depends on cpg density and promoter strength: Evidence for involvement of a methyl-cpg binding protein. Embo J 11(1): 327-333, 1992. PMID: 1310933.

30 Keshet I, Lieman-Hurwitz $\mathbf{J}$ and Cedar H: DNA methylation affects the formation of active chromatin. Cell 44(4): 535-543, 1986. PMID: 3456276.

31 Bird A: The essentials of dna methylation. Cell 70(1): 5-8, 1992. PMID: 1377983.

32 Kobayashi Y, Absher DM, Gulzar ZG, Young SR, McKenney JK, Peehl DM, Brooks JD, Myers RM and Sherlock G: DNA methylation profiling reveals novel biomarkers and important roles for dna methyltransferases in prostate cancer. Genome Res 21(7): 1017-1027, 2011. PMID: 21521786. DOI: 10.1101/ gr.119487.110

33 Kim JH, Dhanasekaran SM, Prensner JR, Cao X, Robinson D, Kalyana-Sundaram S, Huang C, Shankar S, Jing X, Iyer M, Hu M, Sam L, Grasso C, Maher CA, Palanisamy N, Mehra R, Kominsky HD, Siddiqui J, Yu J, Qin ZS and Chinnaiyan AM: Deep sequencing reveals distinct patterns of dna methylation in prostate cancer. Genome Res 21(7): 1028-1041, 2011. PMID: 21724842. DOI: $10.1101 /$ gr.119347.110

34 Rao X, Evans J, Chae H, Pilrose J, Kim S, Yan P, Huang RL, Lai HC, Lin H, Liu Y, Miller D, Rhee JK, Huang YW, Gu F, Gray JW, Huang TM and Nephew KP: Cpg island shore methylation regulates caveolin-1 expression in breast cancer. Oncogene 32(38): 4519-4528, 2013. PMID: 23128390. DOI: 10.1038/onc. 2012.474

35 Irizarry RA, Ladd-Acosta C, Wen B, Wu Z, Montano C, Onyango P, Cui H, Gabo K, Rongione M, Webster M, Ji H, Potash J, Sabunciyan S and Feinberg AP: The human colon cancer methylome shows similar hypo- and hypermethylation at conserved tissue-specific CpG island shores. Nat Genet 41(2): 178-186, 2009. PMID: 19151715. DOI: 10.1038/ng.298

36 Skvortsova K, Masle-Farquhar E, Luu PL, Song JZ, Qu W, Zotenko E, Gould CM, Du Q, Peters TJ, Colino-Sanguino Y, Pidsley R, Nair SS, Khoury A, Smith GC, Miosge LA, Reed JH, Kench JG, Rubin MA, Horvath L, Bogdanovic O, Lim SM, Polo JM, Goodnow CC, Stirzaker C and Clark SJ: Dna hypermethylation encroachment at cpg island borders in cancer is predisposed by $\mathrm{h} 3 \mathrm{k} 4$ monomethylation patterns. Cancer Cell 35(2): 297-314.e298, 2019. PMID: 30753827. DOI: 10.1016/j.ccell.2019.01.004
Received February 18, 2019 Revised March 29, 2019 Accepted April 10, 2019 